\title{
QUEEN'S
UNIVERSITY
BELFAST
}

\section{The solid state of pharmaceuticals}

Edkins, K., \& Cruz-Cabeza, A. (2019). The solid state of pharmaceuticals. CrystEngComm, 21, 2031. https://doi.org/10.1039/C9CE90044F

\author{
Published in: \\ CrystEngComm
}

Document Version:

Peer reviewed version

Queen's University Belfast - Research Portal:

Link to publication record in Queen's University Belfast Research Portal

Publisher rights

copyright 2019 Royal Society Chemistry. This work is made available online in accordance with the publisher's policies. Please refer to any applicable terms of use of the publisher.

\section{General rights}

Copyright for the publications made accessible via the Queen's University Belfast Research Portal is retained by the author(s) and / or other copyright owners and it is a condition of accessing these publications that users recognise and abide by the legal requirements associated with these rights.

Take down policy

The Research Portal is Queen's institutional repository that provides access to Queen's research output. Every effort has been made to ensure that content in the Research Portal does not infringe any person's rights, or applicable UK laws. If you discover content in the Research Portal that you believe breaches copyright or violates any law, please contact openaccess@qub.ac.uk. 


\title{
The Solid State of Pharmaceuticals
}

\author{
Katharina Edkins ${ }^{* a}$ and Aurora J. Cruz-Cabeza ${ }^{*}$ cc
}

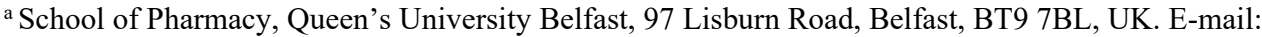 \\ k.edkins@qub.ac.uk \\ b School of Chemical Engineering and Analytical Science, The University of Manchester, Oxford Road, \\ Manchester, M13 9PL, UK. E-mail: aurora.cruzcabeza@manchester.ac.uk \\ c Astra Zeneca, Silk Road Business Park, Charter Way, Macclesfield, SK10 2NA, UK
}

The appearance of different crystal forms has intrigued researchers for decades, and in no field more so than in pharmaceutical materials $[1,2,3]$. Due to the implications to patients' safety and the connected tight regulations of all materials used in pharmaceutical formulation, the physical forms of drug entities are naturally more exhaustively explored than is necessary for other chemicals. Polymorphs [1], hydrates [2] and salts [3] are usual forms explicitly sought and explored in depth through experimental methods often supported by computational methods [4] and structural informatics approaches [5]. Solvates often appear as unwanted products in polymorph screenings or during the design of crystallisation methods [6]. Cocrystals, although also in the game for a while [7,8], have only recently attracted a wider interest for drug delivery what has raised some questions with regards to regulations [9]. In this wealth of solid form universes, much understanding is still sought in the fundamentals that ultimately drive nucleation, growth and the appearance of solid form under a specific set of conditions.

This special issue combines 22 articles touching upon various important issues for the solid state of pharmaceuticals. From the discovery of new polymorphs of well-known drug compounds upon venturing into the non-ambient experimental space to the development of novel crystallisation approaches or the prediction of forms computationally, this collection showcases how far the field has evolved from the phenomenological crystal form screening still performed as standard in pharmaceutical industry and thus indicates where the future of pharmaceutical solid-state might be.

The complex nature of crystal landscapes of pharmaceuticals is impressively shown by Karol Nartowski, Yaroslav Khimyak and coworkers (DOI:10.1039/c8ce01814f) for the antiviral drug acyclovir. The authors investigate the hydrate formation, dehydration behaviour and solvent induced phase transition within this system to reveal the intricate pathways and significant impact of minute changes to experimental conditions. This theme is picked up by Aurora Cruz-Cabeza, Roger Davey et al. (DOI:10.1039/c8ce01890a), who review the polymorphic system of the model compound 4-aminobenzoic acid (pABA), which has been widely used to investigate crystallisation behaviour, nucleation rates and solvent impact. In their sister paper, Martin Ward, Iain Oswald and coworkers (DOI:10.1039/c8ce01882k) pick up the reported prediction data of 4-aminobenzoic acid and realise a novel polymorph of the compound using high pressure crystallography, 50 years after the first crystal structure of this well-studied model compound has been reported. This highlights how the field must embrace non-classical crystallisation methods (i.e. high-pressure) in order to realise novel polymorphs with potentially improved formulation characteristics.

A recent development in the field is the increasing use of ball-mill grinding to effect phase transitions and screen for polymorphs, solvates, cocrystals and salts. Dritan Hasa, Aurora Cruz-Cabeza and coworkers (DOI:10.1039/c8ce02098a) reveal a link between easiness of breaking key crystal planes in the reactant crystals with the kinetics of solvate formation in liquid-assisted grinding. Ana Belenguer et al. (DOI:10.1039/c8ce02098a) explore the conversion of polymorphs upon neat versus liquid-assisted ball-mill grinding for a series of drug compounds. The authors make a link between surface roughness and surface stability which results in smooth polymorphs being more stable at the nanoscale. Also on grinding, the group of Elena Boldyreva (DOI:10.1039/c8ce02109k) investigates the impact of ball size and 
ball mass on the crystal transition of a well-understood co-crystal system. In addition to these two factors, the authors show that chemical surface of the balls have an impact on the studied transition.

The impact of surfaces and impurities, or intentional additives, on the outcome of crystallisations opens another angle to controlling this unit process on the microscopic and the macroscopic scale. Asma Buanz and coworkers (DOI:10.1039/c8ce01780h) use ink jet printing deposited onto different surfaces and spray drying to investigate the impact of the surface chemistry on the polymorphic outcome of D-mannitol. They observed that conditions in which foreign surfaces were able to initiate heterogeneous nucleation would result in the metastable form of D-mannitol whilst conditions favouring homogeneous nucleation would favour the observation of the stable form. Bernhardt Trout et al. (DOI:10.1039/c8ce01517a) show that the use of biocompatible crystalline additives such as L-glutamic acid and histidine can not only increase the nucleation rate but also influence the preferred nucleation of one polymorph of indomethacin over another. Okky Putra, Hidehiro Uekusa and coworkers (DOI:10.1039/c8ce01720d) use magnesium chloride hexahydrate to nucleate a novel polymorph of amodiaquine dihydrochloride dihydrate. These studies showcase the impressive impact of surfaces on crystal polymorphism, which has led the team of Jonathan Steed (DOI:10.1039/c8ce01742e) to investigate supramolecular gels as crystallisation media with tailored polymorphic outcome. The novel gelator presented in this study was shown to influence crystallisation of sulfathiazole into a different crystal form compared to the respective solution.

An alternative to the crystal screening based on serendipity and phenomenology is computational crystal structure prediction (CSP), a computational technique which has developed impressively in the last ten years partly driven by the blind tests organised by the Cambridge Crystallographic Data Centre. Sally Price and coworkers (DOI:10.1039/c8ce01874j) present the application of CSP on the case of $17-\beta$-estradiol in combination with crystallisation studies to obtain an anhydrous structure of the drug compound for the first time. CSP is also used to rationalise the crystallisation behaviour of related compounds, as showcased by Marta Dudek and Graeme Day (DOI:10.1039/c8ce01783b) in the case of the closely related catechin and epicatechin. However, due to the existence of multiple prediction algorithms, the results of CSP are by no means comparable, as outlined by Jonas Nyman and coworkers (DOI:10.1039/c8ce01902a), who show that even though the majority of experimentally realised structures are predicted by two different algorithms, the structures of the remaining predicted crystal forms are not at all the same. The authors also highlight how some density functional models fail to model systems with strong electron delocalization. As a consequence, a seemingly simple pharmaceutical such as ROY turns out to be a challenging system for CSP calculations.

Over the last decades, multi-component crystals have attracted significant attention as a possibility to alter the physicochemical characteristics of the drug compound without changing its chemical structure. The article by Hailu Zhang and coworkers (DOI:10.1039/c8ce01439f) outline the approach of cocrystal screening using the example of stanozolol. Using only four related aromatic carboxylic acid coformers, stanozolol is able to form five different strong hydrogen bond synthons which results in a wealth of solid forms including one salt, two cocrystals, one ionic cocrystal and a mixed hydrate/solvate salt cocrystal. In their study, German Perlovich et al. (DOI:10.1039/c8ce01857j) use the obtained cocrystals of $p \mathrm{ABA}$ to validate thermodynamic predictions of their respective melting points. This approach of linking the melting points of the mixed crystals with those of the coformer has the potential to predict whether a coformer will lead to cocrystal or salt formation. Minas da Piedade et al. (DOI: $10.1039 / \mathrm{c} 8 \mathrm{ce} 02108 \mathrm{~b}$ ) show how solvate formation can impact not only the crystal structure but also the molecular state of drug compounds able to tautomerise. In their work, they show how 5-hydroxynicotinic acid may form a hydrate in a zwitterionic state or a DMSO solvate in a neutral state and they also study the impact of desolvation on the 
molecular structure.Changquan Sun et al. (DOI:10.1039/c8ce01076e) show the fine line and close relationships between salts and cocrystals. In their system of sulfamethazine and saccharine, the same coformer can lead to either a cocrystal or salt as monotropically related polymorphic pair, with the cocrystal being the thermodynamically stable form. Another complication of multi-component crystallisation is showcased by Ashwini Nangia and coworkers (DOI:10.1039/c8ce01075g), who show that depending on the strength of the hydrogen bond formed between indapamide and a coformer, either a cocrystal or a coamorphous phase was obtained. Coamorphous phases show even higher dissolution rates than cocrystals and are thus of significant interest to pharmaceutical industry. In their study on cocrystallisation of 5-fluorouracil, Klaus Merz et al. (DOI:10.1039/c8ce01692e) not only found two novel cocrystals with coformers based on the GRAS list, but also established a novel route to obtain form II of the drug compound, which so far could only be obtained from dry nitromethane, linking this area of research with the impact of surfaces and heteronucleation described earlier. A surprising use of co-crystallisation is reported by Lian $\mathrm{Yu}$, Yanbin Huang, Jun $\mathrm{Xu}$ and coworkers (DOI:10.1039/c8ce01766b). The authors investigate the stability of trigonal carbamazepine form II when including a linear polymer into its channel structure, and utilise the improved stability to investigate crystal growth of this polymorph.

Finally, these more fundamental aspects of crystallisation have a significant impact on the processes following the laboratory-based research and development. Allan Myerson and coworkers (DOI:10.1039/c8ce01428k) show the impact of seeding in batch crystallisation using the model system paracetamol. The team show that just seeding the crystalliser with the desired polymorph (form II) does not necessarily afford polymorph control. Low temperature and low agitation speed were found to allow the crystallisation of form II. The impact of stirring on crystallisation is picked up by Jan Sefcik and coworkers (DOI:10.1039/c8ce01829d), who report that $\gamma$-glycine can be obtained from unstirred aqueous solutions whilst $\alpha$-glycine dominates the crystallisation outcome when stirring is introduced. The influence of drug solid-state on formulation independent of crystal form is impressively shown by Alexei Tivanski and Leonard MadGillivray (DOI:10.1039/c8ce00764k). The team reveals that the Young's modulus of aspirin changes significantly with particle size with smaller crystals being significantly softer and thus better tablettable than larger crystals.

We are grateful for all of the authors contributing to this special issue and to the CrystEngComm editorial office for their support in making it possible.

[1] Haleblian, John, and Walter McCrone. "Pharmaceutical applications of polymorphism." Journal of pharmaceutical sciences 58.8 (1969): 911-929.

[2] Khankari, Rajendra K., and David JW Grant. "Pharmaceutical hydrates." Thermochimica acta 248 (1995): 61-79.

[3] Berge, Stephen M., Lyle D. Bighley, and Donald C. Monkhouse. "Pharmaceutical salts." Journal of pharmaceutical sciences 66.1 (1977): 1-19.

[4] Price, Sarah L. "The computational prediction of pharmaceutical crystal structures and polymorphism." Advanced drug delivery reviews 56.3 (2004): 301-319.

[5] Feeder, Neil, Elna Pidcock, Anthony M. Reilly, Ghazala Sadiq, Cheryl L. Doherty, Kevin R. Back, Paul Meenan, and Robert Docherty. "The integration of solid form informatics into solid form selection." Journal of Pharmacy and Pharmacology 67, no. 6 (2015): 857-868.

[6] Griesser, Ulrich J. "The importance of solvates." Polymorphism in the pharmaceutical industry (2006): 211-233.

[7] Schultheiss, Nate, and Ann Newman. "Pharmaceutical cocrystals and their physicochemical properties." Crystal growth and design 9, no. 6 (2009): 2950-2967.

[8] Shan, N. and Zaworotko, M.J., 2008. The role of cocrystals in pharmaceutical science. Drug discovery today, 13(9-10), pp.440-446.

[9] FDA guideline: Regulatory Classification of Pharmaceutical Co-Crystals - Guidance for Industry February 2018 